\title{
Condições psicológicas para a observação das terapias antiretrovirais altamente ativas (HAART)
}

\author{
Doris Vasconcellos* \\ Odile Picard** \\ Sarah Cohen Ichaï
}

\section{INTRODUÇÃO}

Todos os pacientes sofrendo de doenças crônicas reconhecem ter dificuldade para seguir o tratamento prescrito, mas, no caso das HAART, o perigo ligado ao desenvolvimento de cepas virais resistentes ao tratamento constitui um risco direto para o próprio paciente e para a saúde pública ${ }^{1}$. Espera-se que o paciente siga o tratamento, fonte de esperança, apesar da apreensão ligada aos efeitos secundários e aos fracassos terapêuticos. Entretanto, a observação $o^{a}$ do tratamento nunca pode ser considerada como definitivamente estabelecida, pois cada dia o paciente pode ter seu comportamento desestabilizado por inúmeras razões, tanto de ordem prática quanto de ordem psicológica. Podemos considerar que o primeiro ano de tra-

\footnotetext{
* Psicólogas Universidade Paris V.

** Médica, especialista de AIDS no Hospital Saint-Antoine.

a Mantive o termo observação do tratamento ao invés de adesão ou aderência. Aderir ao tratamento não significa necessariamente cumprir, observar a prescrição. O paciente pode aderir ao tratamento e não tomar os comprimidos por diversas razões. 0 que interessa é o resultado final, 0 ato de ingerir dentro das condições prescritas.
}

tamento constitui um período crítico para o estabelecimento de estratégias adaptativas que vão permitir que o paciente se aproprie deste comportamento e o integre à sua vida cotidiana. Nossa pesquisa interessou-se em estudar esta fase inaugural para discriminar quais os fatores psicológicos que favorecem e os que perturbam este processo.

Os pesquisadores em Psicologia da Saúde $^{2-4}$ constataram que a auto-estima, o apoio social, a depressão e a gestão do controle e da autonomia $^{b}$ estão correlacionados com o comportamento de observação do tratamento no caso de doenças crônicas. Estas variáveis foram avaliadas com instrumentos do tipo escalas ou questionários, os quais são altamente dependentes do fenômeno de conformismo social. Sobretudo, esta metodologia não permite compreender a articulação dinâmica que se estabelece entre as variáveis estudadas. Adotamos um enfoque psicanalítico que permite desvendar o conteúdo latente que determina a

${ }^{\mathrm{b}} \mathrm{O}$ conceito de locus of control se refere à atribuição que o sujeito faz do que é determinante para a sua vida. Locus interno: sua decisão e vontade; locus externo, o destino, a sorte e outros elementos incontrolaveis.

Recebido em 05/10/2002. Revisado em 08/10/2002. Aprovado em 09/09/2003. 
dinâmica do comportamento. Como vimos, a dimensão temporal é essencial à compreensão dos fatores ligados à estabilidade do comportamento, tendo sido necessário aplicar um protocolo longitudinal para levar em conta esta variável $^{5}$.

Sabemos que todos os doentes crônicos necessitam de apoio social. No que concerne ao HIV em particular, a dimensão relacional constitui o âmago da problemática psicológica destes pacientes, pois, o fato de o vírus ser transmissível hipoteca definitivamente as relações humanas dos contaminados potencialmente contaminantes.

As especificidades do objeto de estudo impõem a escolha metodológica. Duas linhas de força são incontornáveis: a dimensão relacional por um lado e a dimensão temporal pelo outro.

\section{METODOLOGIA}

A observação do tratamento médico decorre da experiência original que cada paciente elabora a partir de sua organização psíquica para integrar a vivência da doença e se relacionar com o seu meio afetivo, com o apoio inclusive da equipe que o trata.

Este ponto de vista privilegia a subjetividade do sujeito confrontado a pressões incontornáveis que o obrigam a elaborar um compromisso pessoal, o qual, no melhor dos casos, permite que ele se aproprie da prescrição. A este propósito é interessante lembrar o processo de subjetivação da doença descrito por D. Silvestre, F. Leguil e F. Linard ${ }^{6}$. A nova etapa inaugurada pelo tratamento também será integrada segundo as modalidades subjetivas próprias a cada paciente.

O comportamento de observação do tratamento está sujeito a múltiplas intromissões. Seu sucesso depende da adesão pessoal, relativamente mais protegida dos desvios suscitados pelas contigências da vida ${ }^{7}$. Entretanto, o grau de adesão só pode ser medido de maneira objetiva através do comportamento de observação do tratamento. Portanto, ainda que o objetivo final seja estabelecer a adesão, uma pesquisa só pode avaliar a observação do tratamento.

Levando em conta que esta pesquisa oferece resultados individuais diretos baseados na observação do tratamento, consideramos o paciente como sujeito ativo e parceiro diretamente interessado no desenvolvimento e nos resultados do processo. A pesquisa é proposta em termos de uma colaboração para compreender como se pode gerenciar um tratamento a longo ressam tanto quanto as dificuldades encontradas. Essa ponderação entre as condutas de fracasso e de sucesso parece favorecer no paciente a tomada de consciência de seus próprios meios de controle sobre a realização do tratamento.

A investigação longitudinal efetua-se em 4 tempos ao longo do primeiro ano de tratamento:

T1: Inclusão ${ }^{c}$ no momento da primeira prescrição de HAART. Uma entrevista clínica de 45 minutos, gravada e retranscrita, explora as variáveis observadas nas pesquisas sobre a observância : auto-estima, apoio social, depressão e lugar de controle, tanto no contexto atual quanto na história do paciente. Com efeito, estas variáveis interagem entre elas e seus pesos são nitidamente diferentes, conforme constatamos.

Para situar estas variáveis em relação à organização psíquica de base, aplicamos os testes projetivos Rorschach e T.A.T. (Thematic Apperception Test). A avaliação dos testes projetivos segundo a teoria psicanalítica ${ }^{8,9}$ foi realizada às cegas, isto é, a psicóloga encarregada de interpretá-los não tinha conhecimento dos dados da entrevista.

T2: Quatro meses depois, uma segunda entrevista permitia acompanhar a instalação do tratamento e as primeiras reações do paciente, inclusive como eram vividos os efeitos secundários.

T3: Quatro meses depois do T2, uma terceira entrevista dava ao paciente a ocasião de refletir sobre os eventuais desvios e dificuldades encontradas, assim como sobre as estratégias utilizadas para proteger a observação.

T4: Ao cabo de um ano de tratamento, uma quarta entrevista seria realizada para fazer um inventário dos resultados, os elementos de satisfação, assim como os fatores que pertubaram a observação do tratamento.

A limitação das variáveis permanece o argumento metodológico essencial para esclarecer nossa escolha de funcionar em pequena equipe, face a uma problemática tão dependente das relações humanas, conforme constatamos. Esta precaução permite supor que as variações encontradas no comportamento de observação do tratamento podem ser atribuídas principalmente aos pacientes e à sua vivência da doença, uma vez que a equipe de atendimento (médica, psicóloga, enfermeiras) permanece constante. A confiabilidade do

c Os pacientes foram recrutados pela Dra. Odile Picard na Policlinica do Hospital Saint-Antoine em Paris. 
acompanhamento longitudinal depende dessa condição.

Ao cabo do primeiro ano de tratamento, uma síntese da evolução de cada paciente foi então comparada com os resultados das análises de biologia médica realizadas paralelamente para o acompanhamento clínico. Para os pacientes que abandonaram nosso protocolo de pesquisa, dispomos dos dados biológicos que permitem inferências sobre a relação da observação do tratamento com a carga viral ${ }^{10}$.

Tratando-se de uma pesquisa qualitativa, não julgamos necessário que o grupo observado fosse homogêneo do ponto de vista da idade, do sexo ou do modo de contaminação. A análise dos resultados situa estas variáveis no seu contexto. Recrutamos dezenove pacientes (quadro 1) muito representativos da população contaminada na França, tanto quanto ao sexo (5 mulheres, 14 homens), à idade (26 a 68 anos, mediana 36 ), ao modo de contaminação (12 homosexuais, 6 heterosexuais, 1 dependente de drogas injetáveis - DDI), de todos os níveis sócio-econômicos e culturais. O critério essencial de inclusão na pesquisa foi o fato de estar começando uma HAART. A maioria das pessoas que compunham este grupo (16 sobre 19) era constituída por pacientes que nunca tinham realizado tomado um tratamento específico contra o HIV. O critério essencial de exclusão era a presença de uma psicose ou de perturbações psiconeurológicas. Nenhum paciente que aceitou participar teve de ser afastado por estes critérios.

Entre os 19 pacientes incluídos no protocolo, 14 foram acompanhados ao longo do primeiro ano de tratamento. Constatamos, portanto, uma perda de $25 \%$ dos efetivos: 5 dos 19 pacientes abandonaram o protocolo após a segunda entrevista. Esta porcentagem permanece abaixo da média, pois estima-se que pelo menos $30 \%$ dos pacientes são perdidos nos acompanhamentos longitudinais publicados ${ }^{7}$. Quatro pacientes em condições de precariedade $(20 \%$ do grupo - Sofia, Cirilo, Dominique e Camille) aceitaram participar e somente um deles (Cirilo) abandonou após a segunda entrevista.

A análise dos dados recolhidos (entrevistas, testes e exames biológicos) conduziu-nos a tratar os resultados em duas seções.

\section{RESULTADOS}

\section{A. Resultado global da observação (quadro 2)}

Nossa amostra confirma a estabilidade do comportamento de observação, conforme várias pesquisas citadas por J. M. Dunbar-Jacob et al. ${ }^{11}$. A estabilidade revela-se positiva no caso de 9 pacientes que tomaram mais de $90 \%$ das doses durante o primeiro ano.

O progresso na apresentação dos medicamentos repercutiu diretamente na observação da HAART. Três pacientes às quais foram prescritas apenas duas doses - dois comprimidos pela manhã e à noite - reportam ter ingerido todas as doses prescritas durante o primeiro ano.

Notamos que os efeitos secundários parecem determinar apenas um caso de interrupção após 4 meses de tratamento. Assim mesmo, esta constatação é discutível, pois os três primeiros meses foram bem tolerados e outros fatores coincidem com esta interrupção, conforme veremos. Os outros 3 casos de interrupção produziram-se com pacientes que sempre toleraram bem os medicamentos.

\section{B. Problemáticas encontradas \\ 1. A relação entre a auto-estima e 0 apoio social}

Para apresentar os resultados desta pesquisa, pareceu-nos fecundo apreender a autoestima como o ponto de articulação invisível que organiza as respostas adequadas para atrair as relações de apoio, lutar contra a depressão e assegurar o controle do comportamento, particularmente das atividades de autoproteção, tais como a observação do tratamento.

A pesquisa de G.Lévêque ${ }^{12}$ mostra a diminuição da auto-estima dos soropositivos em relação ao grupo-controle no tocante às avaliações ligadas ao futuro e aos campos social, profissional e emocional. Esta constatação permite correlacionar o risco de depressão à baixa da auto-estima, isto é, à impressão de não corresponder às suas próprias expectativas nos campos considerados. Controlar a observação do tratamento só tem sentido se o sujeito considera sua vida satisfatória ou, pelo menos, encontra razões para ter esperanças.

Entretanto, a auto-estima não pode se man- 
ter sem se apoiar sobre as confirmações oferecidas pelas pessoas significativas. Se o fato de ser transmissível distingue o HIV como uma doença que se inscreve na relação, este contexto de exigência de um trabalho psíquico pessoal para se manter o tratamento aumenta a vulnerabilidade relacional: partilhar o segredo ligado aos medicamentos, e portanto à contaminação, torna-se crucial para a observação do tratamento. Quem está a par do tratamento? Quais são as conseqüências sobre a observação?

\section{Partilhar o segredo}

a) Os depositários do segredo

No momento de começar o tratamento, a gestão do segredo sobre a contaminação permanece um problema para a maioria dos pacientes. O segredo deve ser posto em relação com o medo de perder os recursos afetivos que são indispensáveis para sustentar a auto-estima:

"Não quero passar pela bicha do escritório." Sérgio, 28 anos, soropositividade conhecida há 8 anos, primeira entrevista.

Na nossa amostra de 19 pacientes:

- Dois pacientes comunicaram sem dificuldade início do tratamento aos seus amigos próximos.

- Cinco comunicaram a um membro da família.

- Seis colocaram somente dois ou três amigos a par.

- Quatro não falaram disto com ninguém fora do casal.

- Dois não contaram para ninguém.

Três pacientes relatam não haver perdido nenhuma dose durante o primeiro ano de tratamento. Vimos que se trata da última geração de medicamentos que exigem apenas duas doses cotidianas. O fato de que se trata de mulheres é sem dúvida uma coincidência, pois até hoje nenhuma pesquisa publicada pôde determinar uma correlação entre a observação do tratamento e as características sócio-demográficas da amostra ${ }^{13}$. Estas 3 mulheres têm em comum a particularidade de viver com homens que elas consideram muito atenciosos. Dois deles são soropositivos também. Observamos que, dos 7 pacientes vivendo com um parceiro que está a par do tratamento, 5 são nitidamente mais regulares (mais de $90 \%$ das doses), independentemente do status sorológico do parceiro.
Tomar medicamentos regularmente pode complicar muito a situação daqueles que desejam conservar o segredo da contaminação. Cinco parceiros estáveis não estão a par da contaminação no momento da primeira prescrição. Quatro pacientes não falam deste assunto com os parceiros eventuais.

b) Conseqüências das estratégias de partilha do segredo sobre a observação do tratamento

Pode-se compreender que os pacientes que não partilham a informação com o círculo íntimo são obrigados a inventar estratégias muito complicadas para tomar todas as doses.

$\mathrm{Na}$ impossibilidade de esconder um tratamento tão pesado ao amigo mais íntimo, a instauração da terapia pode provocar a revelação do status sorológico do casal. Diferentes resultados podem se produzir. No melhor dos casos, esta descoberta mútua pode então reforçar a relação e aliviar a tensão, facilitando a observação do tratamento que é assim integrado à relação: um paciente entrou em competição amigável com seu parceiro pelos melhores resultados nos exames biológicos.

Em geral, os critérios para escolher os depositários do segredo não levam em conta seu eventual papel para facilitar ou perturbar a observação. A escolha dos depositários do segredo responde prioritariamente às necessidades afetivas, e sua reação vai confirmar a importância da relação ou trazer uma decepção.

Se partilhar o segredo pode facilitar a observação, depender da apreciação do outro pode prejudicar o processo se o depositário do segredo duvida da eficácia do tratamento ou insiste sobre os riscos dos efeitos secundários. Pode-se pensar que o paciente é mais frágil no início do tratamento enquanto os resultados positivos ainda não são evidentes para contrabalançar sua incerteza, mas a vulnerabilidade psíquica que predispõe a se deixar influenciar não se baseia em elementos objetivos. $\mathrm{Na}$ maioria dos casos, a escolha dos depositários do segredo não parece evoluir com o passar do tempo.

\section{c) A aliança terapêutica}

Muitas pesquisas insistem sobre o impacto da relação médico-paciente sobre a observação do tratamento. Quer seja do ponto de vista da estratégia de apresentação do tratamento, quer da relação de confiança ou da solidez da aliança terapêutica ${ }^{14}$, a maioria das pesquisas 
que concernem aos elementos correlacionados com a observação da HAART lembram esta forma específica de apoio social.

Vários pacientes mencionaram espontaneamente o vinculo de confiança que os liga ao médico. Essa confiança se constrói sobretudo de maneira subliminar pela atitude do médico durante a consulta. Quando se pergunta aos pacientes em que circunstâncias perceberam este fator, observa-se que a discussão dos efeitos secundários é um momento capital : nem dramatizar nem banalizar; o equilíbrio é delicado.

A atenção dispensada às expectativas conscientes dos pacientes também responde à necessidade inconsciente regressiva de ser tranqüilizado pela onipotência projetada na prescrição do médico.

A idéia de permanecer sob tratamento pelo resto da vida, noção própria à doença crônica, é temperada, no caso da HAART, por dois elementos de informação que facilitam a aceitação psicológica: os tratamentos já estão sendo consideravelmente melhorados desde sua aparição em 1995, e novos progressos científicos significativos são esperados a médio prazo. Não se pode negligenciar o impacto desta informação, se lembramos o isolamento afetivo imposto pelo segredo que cobre a contaminação.

\section{d) As figuras da depressão}

Sabemos que, mesmo para os pacientes que sabem que estão contaminados há anos, a introdução da HAART significa uma mudança na vivência da contaminação. Esta indicação representa um limiar no curso da infecção, marcando a degradação constatada dos parâmetros biológicos.

Portanto, não é surpreendente que os testes projetivos mostrem sinais de depressão em 13 dos 19 pacientes, entre os quais 6 que souberam que estavam contaminados há pouco tempo. A depressão pode permanecer latente e não ser reconhecida pelos pacientes, ocultada por mecanismos de defesa do tipo evitação ou recusa da realidade.

Para 7 dos pacientes de nossa amostra (mais de um terço), a prescrição praticamente coincide com o traumatismo da revelação da soropositividade, pois a indicação da HAART foi colocada entre 2 semanas e 4 meses depois da notificação. Pelo menos 4 destes pacientes acabaram lembrando ter observado sintomas suspeitos que foram negligenciados na vã tentativa de se proteger pela recusa da realidade.

Esta configuração - início do tratamento seguindo a descoberta da soropositividade condensa a vivência de dois choques emocionais desestabilizadores, mas o tratamento proposto imediatamente também pode tranqüilizar aqueles que pensam poder exercer assim um controle sobre seu estado de saúde.

A complexidade desta prova psicológica deve ser analisada, levando em conta o risco de depressão ocasionado pela estratégia de defesa pela repressão. Para aqueles que quiseram ignorar os sintomas precursores, a revelação da soropositividade revela o fracasso da repressão na tomada de consciência desta realidade e leva à depressão pela confrontação com a impotência, isto é, pela constatação da ineficácia dos mecanismos de controle que o paciente utiliza. A auto-estima sofre inevitavelmente.

Um outro caso de figura preocupante concerne aos pacientes que se inscrevem numa história de depressão latente instalada há vários anos:

“... freqüentemente pensei em me matar, até tentei, mas é preciso muita coragem ou muita... não sei se é preciso chamar isto de coragem ou desespero..." Cirilo, 34 anos, soropositividade conhecida há 9 anos, primeira entrevista.

Na ausência de uma dinâmica interiorizada, a continuidade da observação permanece ameaçada por uma eventual falha do meio relacional que provocaria um desequilíbrio nesta estabilidade precária.

\section{e) O lugar de controle}

Todos os estudos que se interessam pelas variáveis correlacionadas com a observação do tratamento médico evocam sistematicamente o apoio social e a depressão. O mesmo não ocorre com o lugar de controle. Parece lógico que, se uma pessoa se estime capaz de controlar seu tratamento e esteja disposta a fazê-lo, possa conseguir. Entretanto, esta determinação declarada antes da experiência pessoal do tratamento pode se modificar sensivelmente depois. Com efeito, o paciente pode se considerar consciente das exigências implicadas:

"É verdade que não é fácil assumir um tratamento todo o tempo. Eu tenho muita força de vontade, eu acho que vai dar. $\mathrm{Na}$ vida eu sempre soube lutar, portanto vou continuar, é isto que eu digo. (...) eu assumo a minha doença." Joel, 30 anos, soro- 
positividade conhecida há 7 anos, primeira entrevista.

O discurso consciente, neste primeiro momento, indica que o paciente considera possível a observação (expectativa de resultado) e mostra uma vontade decidida a controlar a situação que ele considera como estando ao seu alcance (expectativa de eficácia). O resultado objetivo não é correspondente:

"Tomei um pouco e depois eu pensei que chegava, daí eu comecei a ter problemas de pele e tudo, então fiquei preocupado, achei que não funcionava, enchi do tratamento." Joel, 30 anos, segunda entrevista, 17 meses depois da primeira prescrição.

Parece-nos que o lugar de controle é, dentre as quatro variáveis que examinamos, a mais diretamente submetida à conformidade social : - paciente sabe que esperamos que ele se mostre responsável pelo seu tratamento e deseja mostrar-se conforme nossas expectativas.

A pesquisa de M.R.Kraus et al. ${ }^{15}$ cruzando a qualidade das relações interpessoais e o lugar de controle chegou a duas conclusões interessantes: por um lado, o lugar de controle avaliado através de escalas não diferia do grupo controle de pacientes sem queixa somática e mostrava-se predominantemente interno; por outro lado, os pacientes apresentando dificuldades na observação do tratamento manifestavam mais problemas interpessoais, tanto anteriormente quanto no momento de começar o tratamento. Nossa amostra confirma esta conclusão de prevalência da qualidade das relações afetivas na problemática da observação do tratamento médico.

\section{f) As rupturas da observação}

O paciente integra a informação racional sobre o tratamento, segundo as defesas que utilizou para enfrentar a doença e segundo os mecanismos de controle mais ou menos vulneráveis às perturbações da vida cotidiana.

Quanto mais rápidos e efetivos os resultados, mais o paciente se tranqüiliza. Resultados encorajadores trazem uma retroação positiva ao comportamento de observação. Nos melhores casos, esta confirmação objetiva pode alimentar a auto-estima e consolidar a adesão pessoal ao tratamento. Entretanto, esta recuperação biológica extraordinária pode dar lugar a um efeito paradoxal, pois alimentando certas fantasias onipotentes, a observação pode ser desmobilizada.

Dois pacientes aos quais estavam prescritas 3 doses diárias relataram em todas as entrevistas ter esquecido sistematicamente pelo menos 4 ou 5 doses por semana. Pode-se temer que o número de doses seja ainda maior do que o relatado, pois G.J.Wagner et J.G.Rabkin ${ }^{16}$ constataram que, mesmo os pacientes que se declaravam não-observadores, superestimavam a quantidade de doses absorvidas. Mas os resultados biológicos destes dois pacientes são satisfatórios e se tornam assim um argumento decisivo para a negligência descrita como involuntária, sem que no entanto se observe nenhuma preocupação de retificação.

$\mathrm{Na}$ nossa amostra, observamos 4 pacientes que interromperam o tratamento durante 0 primeiro ano por períodos entre 2 e 6 meses. Assim que retomaram o tratamento, os resultados biológicos se restabeleceram no melhor nível em poucas semanas. Não se pode prever quais podem ser as conseqüências biológicas desta oscilação do comportamento. Esses pacientes evocam circunstâncias que explicam estas interrupções. Em cada um destes casos, a relação afetiva parece o pivô essencial que desencadeou este acontecimento:

- Dominique parou no momento em que morreu seu amigo que não teve acesso ao tratamento.

- Maurício parou durante as férias que passou na casa de amigos íntimos, que o preveniam reiteradamente sobre os efeitos secundários dos medicamentos. Muito bem adaptado até então, os efeitos colaterais anunciados se desencadearam nestas circunstâncias.

- Para Cláudio, coincide a perda do emprego com o AVC do tio que o tinha criado e a ruptura da relação com o parceiro soropositivo (em competição pelos melhores resultados biológicos ao tratamento).

- Joel não podia comunicar a contaminação - e menos ainda o tratamento - ao parceiro da época. O medo de perder a fonte indispensável de confirmação afetiva torna a confrontação impossível. Para este paciente, a mesma situação recomeça com o novo parceiro:

“...ele não está a par, e como tudo vai bem ele não precisa saber ... eu tomo os remédios no escritório quando chego e de tarde, a mesma coisa, tomo antes de sair." (segunda entrevista, 17 meses depois do começo do tratamento). 
Para completar a leitura psicanalítica proposta pela nossa metodologia, é preciso evocar o ponto de vista econômico que concerne aos fenômenos relativos ao equilíbrio psicossomático. Se a dinâmica relacional parece uma hipótese plausível para explicar as rupturas do tratamento, devemos levar em conta também a gerência econômica dos conflitos, isto é, o limiar individual que limita a capacidade do sujeito para elaborar a ansiedade provocada pelos acontecimentos da vida através dos mecanismos psíquicos de defesa. Ultrapassada a capacidade de mentalização, abrem-se as vias das duas outras regulações menos adaptadas: o comportamento impulsivo ou, mais grave ainda, a somatização. Livrar-se da sujeição representada pela observação do tratamento como reação a outras sujeições impossíveis de evitar pode dar ao sujeito a ilusão de recuperar o controle fantasioso sobre um aspecto importante da sua vida.

\section{CONCLUSÃO}

A dimensão longitudinal do nosso estudo, assim como a metodologia qualitativa utilizada, tornam difícil compará-lo com a maioria dos estudos sobre as características psicológicas ligadas ao comportamento de observação avaliadas com uma metodologia quantitativa através de escalas e questionários. Entretanto, podemos destacar alguns pontos de reflexão.

Para a maioria dos pesquisadores, a primeira causa de interrupção da HAART é atribuída aos efeitos secundários intoleráveis. Esta reação dos pacientes é bem compreensível e pode assim representar uma racionalização aceitável da ruptura, ocultando desta maneira outras determinações subjacentes. Entretanto, em 3 dos 4 casos de ruptura durante o primeiro ano de tratamento, na nossa amostra, não havia queixa de efeitos colaterais e o tratamento era bem tolerado. Constatamos que a ruptura foi determinada por uma dinâmica mais complexa ligada às flutuações do apoio representado pelas relações afetivas, mais prioritárias no imediato do que a observação do tratamento. A falha deste apoio perturba diretamente a gerência do tratamento, tanto mais que as conseqüências desta interrupção não são constatadas imediatamente e podem ser recusadas pela consciência.

A análise dos testes projetivos mostra que nenhuma característica pessoal, tais como a resistência à frustração, o controle da impulsividade ou a capacidade de auto-observação, revelou-se correlacionada de maneira sistemáti- ca no tempo para os nossos pacientes. Outros autores também o constataram. J.Dunbar-Jacob et cols ${ }^{11}$ apresentam um estudo randomizado realizado na Clínica de Pesquisa sobre os Lipídios para a Prevenção Coronária Primária com acompanhamento dos pacientes durante 7 anos. Nem a depressão apresenta correlação longitudinal estável nestes resultados. Pensamos ter demonstrado que existe um mecanismo de compensação possível da depressão que foi observado na nossa amostra, particularmente com as três pacientes citadas. Parece-nos que a depressão e a ansiedade, assim como a impulsividade, não provocam rupturas do tratamento enquanto puderem ser compensadas por relações de apoio satisfatórias. Podemos concluir que, se as rupturas do tratamentos se esclarecem a posteriori pelo contexto relacional, não parece haver indicadores a priori para fundamentar um prognóstico confiável da observação do tratamento.

Se podemos considerar a infecção pelo HIV como uma doença crônica comparável a outras que exigem um tratamento cotidiano complexo, seria instrutivo aplicar este protocolo de pesquisa a amostras de populações que não estão submetidas às problemáticas devidas ao fato de a doença ser transmissível para compreender as similitudes e as diferenças ligadas à observação do tratamento.

\section{REFERÊNCIAS BIBLIOGRÁFICAS}

1. Houyez F. Résistances et stratégies thérapeutiques. Journal du sida, $118: 5-6,1999$.

2. Morin M, Moatti J.-P. Observance et essais thérapeutiques : obstacles psychosociaux dans la recherche sur le traitement de l'infection par le VIH. Nature - Sciences Sociétés, 4 (3) : 228-240, 1996.

3. Visintini R, Fossati A, Bagnato M, Novella L, Brignone S, Pozzoli S, Rossi D, Tambussi G, Maffei C. Compliance to treatment and its relationship with personality disorderds in HIV-positive patients. 2nd European conference on the methods and results of social and behavioural sciences. AIDS in Europe. New challenges for social and behavioural Sciences, Paris, 1998.

4. White NE, Richter J, Fry C. Coping, social support and adaptation to chronic illness. Western Journal of Nursing Research, vol.14 (2):211-224, 1992.

5. Vasconcellos D. SIDA: l'observance du traitement par la trithérapie - conditions psychologiques. L'Information Psychiatrique, $1: 55-63,2000$.

6. Silvestre D, Leguil F, Linard F. Le SIDA, une rupture pour le sujet. Sciences sociales et santé, vol.VII(1) :81-93, 1989.

7. Abelhauser A. Observance, compliance ou adhésion? Enjeux sociaux et mécanismes psychiques. $2^{\text {nd }}$ European conference on the methods and results of social and behavioural sciences. AIDS in Europe. New challenges for social and behavioural sciences, Paris, 1998.

8. Chabert C. Les méthodes projectives en psychosomati- 
que. Encyclopédie médico-chirurgicale, Psychiatrie, 6, 37400 D 10, 1988

9. Shentoub V et al. Manuel d'utilisation du T.A.T.: approche psychanalytique. Dunod:Paris, 1990.

10. Chesney M, Morin M, Sherr L. Adherence to HIV combination therapy. Social Sciences and Medecine, vol 50, $11: 1599-1605,2000$.

11. Dunbar-Jabob JM, Schllenk EA, Burke LE, Matthews JT. Predictors of patient adherence: Patient characteristics. In: Shumaker, S.A. et al. The handbook of health behaviour changes. Springer publishing company:New York, 1998.

12. Lévêque G. Estime de soi et séropositivité. In: Bolognini, M.; Prêteur, Y. Estime de soi, perspectives développementales. Delachaux et Niestlé:Lausanne, 1998.

13. Bakken S, Holzemer WL, Brown MA, Powel-Cope GM, Turner JG, Inouye J, Nokes KM, Corless IB. Relationships between perception of engagement with health care provider and demographic characteristics, health status and adherence to therapeutic regimen in persons with HIV/ AIDS. AIDS Patient Care and STD's, vol 14(4):189-197, 2000.

14. Tsasis P. Adherence assessement to highly active antiretroviral therapy. AIDS patient care and STD's, vol 15(3) :109-115, 2001.

15. Kraus MR, Schafer A, Faller $H$, Scheurlen M, Csef $H$. Locus of control interpersonal problems and therapy compliance in patients with chronic hepatitis $C$ virus infection. Zeitschrift fur klinische psychologie psychiatrie und psychotherapie, 48(3):302-320, 2000.

16. Wagner GJ, Rabkin JG. Measuring medication adherence: are missed doses reported more accurately than perfect adherence? AIDS-Care vol 12(4):405-408, 2000.

\section{RESUMO}

Esta pesquisa longitudinal estudou a organização psíquica dos indivíduos, gestionários de um tratamento complexo, confrontados às dificuldades da vida cotidiana, durante o primeiro ano de tratamento pela terapia antiretroviral altamente ativa (HAART). O objetivo da pesquisa era o de discriminar os fatores que favorecem e os que perturbam este processo. Constata-se a importância determinante das relações de apoio para confortar a estima de si que dá sentido ao esforço de prosseguir o tratamento.

Descritores: HIV, AIDS, tratamento, condições psicológicas.

\section{ABSTRACT}

This longitudinal qualitative research studied psychological conditions patients are required to have in order to manage HAART. It intended to discriminate features that contribute and those that hinder this process. It acknowledges the outstanding role of supportive relationships in making patients comply with the treatment.

Keywords: HIV, AIDS, treatment, psychological environment.

Title: Psychological conditions for HAART

\section{RESUMEN}

Esta pesquisa longitudinal estudió la organización psíquica de los individuos, cuestionarios de un tratamiento complejo, confrontados a las dificultades de la vida cotidiana, durante el primer año de tratamiento por la terapia antiretroviral altamente activa (HAART). El objetivo de la pesquisa era discriminar los factores que favorecen y los que perturban este proceso. Se constata la importancia determinante de las relaciones de apoyo para confortar la estima de sí que da sentido al esfuerzo de proseguir el tratamiento.

Palabras-clave: HIV, SIDA, tratamiento, condiciones psicológicas.

Título: Condiciones psicológicas para la observación de las terapias antiretrovirales altamente activas (HAART)

Endereço para correspondência:

Doris Vasconcellos

Maître de Conférences

Institut de Psychologie

Université René Descartes

71, Av. Édouard Vaillant

92100 - Boulogne-Billancourt - France

Copyright (c) Revista de Psiquiatria do Rio Grande do Sul - SPRS 
Quadro 1 - Características clínico-demograficas dos pacientes

\begin{tabular}{|c|c|c|c|c|}
\hline Pacientes & Origem & $\begin{array}{l}\text { Modo de } \\
\text { transmissão }\end{array}$ & $\mathrm{VIH}$ + desde & Ocupação \\
\hline $\begin{array}{l}\text { Gisela } \\
26 \text { anos }\end{array}$ & Nigéria & Hétero & 3 meses & Estudante \\
\hline $\begin{array}{l}\text { Sérgio } \\
28 \text { anos }\end{array}$ & Paris & Homo & 2 anos & Empregado \\
\hline $\begin{array}{l}\text { Eduardo } \\
28 \text { anos }\end{array}$ & Paris & Homo & 8 anos & Artesão \\
\hline $\begin{array}{l}\text { Joel } \\
30 \text { anos }\end{array}$ & Província & Homo & 7 anos & Empregado \\
\hline $\begin{array}{l}\text { Fabiana } \\
33 \text { anos }\end{array}$ & Guiné & Hétero & 2 semanas & Empregado \\
\hline $\begin{array}{l}\text { Sofia } \\
34 \text { anos }\end{array}$ & $\begin{array}{l}\text { Costa do } \\
\text { Marfim }\end{array}$ & Hetero & 1 mês & $\begin{array}{l}\text { Professora } \\
\text { Primária }\end{array}$ \\
\hline $\begin{array}{l}\text { Cláudio } \\
34 \text { anos }\end{array}$ & Província & Homo & 2 semanas & Empregado \\
\hline $\begin{array}{l}\text { Cirilo } \\
34 \text { anos }\end{array}$ & Província & U.D & 9 anos & Desempregado \\
\hline $\begin{array}{l}\text { Sebastião } \\
34 \text { anos }\end{array}$ & Oriente Médio & Homo & 3 meses & Estudante \\
\hline $\begin{array}{l}\text { Edmundo } \\
36 \text { anos }\end{array}$ & Província & Homo & 4 meses & Empregado \\
\hline $\begin{array}{l}\text { Leonardo } \\
39 \text { anos }\end{array}$ & Província & Homo & 4 anos & Funcionário \\
\hline $\begin{array}{l}\text { Elizabeth } \\
40 \text { anos }\end{array}$ & Província & Hetero & 1 ano & Empregado \\
\hline $\begin{array}{l}\text { Camile } \\
46 \text { anos }\end{array}$ & Equador & Homo & 10 anos & $A P S^{*}$ \\
\hline $\begin{array}{l}\text { Luis } \\
47 \text { anos }\end{array}$ & Antilhas & Hétero & 1 anos & Empregado \\
\hline $\begin{array}{l}\text { Paulo } \\
48 \text { anos }\end{array}$ & Província & Homo & 3 anos & Artesão \\
\hline $\begin{array}{l}\text { Dominique } \\
51 \text { anos }\end{array}$ & Equador & Homo & 2 anos & $A P S^{*}$ \\
\hline $\begin{array}{l}\text { Juarez } \\
56 \text { anos }\end{array}$ & Província & Homo & 13 anos & funcionário \\
\hline $\begin{array}{l}\text { Maurício } \\
57 \text { anos }\end{array}$ & Paris & Homo & 1 mês & Aposentado \\
\hline $\begin{array}{l}\text { Yvon } \\
68 \text { anos }\end{array}$ & Senegal & Desconhecido & 3 anos & Aposentado \\
\hline
\end{tabular}

* Autorização provisória de estadia por motivo de saúde.

${ }^{1}$ Os nomes dos pacientes foram trocados para preservar o anonimato. 
Quadro 2 - Características de evolução dos pacientes

\begin{tabular}{|c|c|c|c|c|c|}
\hline Pacientes & $\begin{array}{l}\text { Primeira } \\
\text { Prescrição }\end{array}$ & $\begin{array}{l}\text { Efeitos } \\
\text { Secundários }\end{array}$ & Observação & $\begin{array}{l}\text { Evolução da } \\
\text { Prescrição }\end{array}$ & $\begin{array}{l}\text { Evolução da } \\
\text { Observação }\end{array}$ \\
\hline $\begin{array}{l}\text { Gisela } \\
26 \text { anos }\end{array}$ & 2 doses & Bem tolerado & & & $\begin{array}{l}\text { Nenhuma dose } \\
\text { perdida em } 12 \text { meses }\end{array}$ \\
\hline $\begin{array}{l}\text { Sérgio } \\
28 \text { anos }\end{array}$ & 3 doses & Bem tolerado & $\begin{array}{l}\text { Mais de } 90 \% \\
\text { das doses }\end{array}$ & $\begin{array}{l}\text { Passou a } 2 \text { doses } \\
\text { depois do início do } \\
\text { Tratamento }\end{array}$ & $\begin{array}{l}\text { Mais de } 90 \% \text { das doses } \\
\text { nos } 14 \text { primeiros meses }\end{array}$ \\
\hline $\begin{array}{l}\text { Eduardo } \\
28 \text { anos }\end{array}$ & 2 doses & Bem tolerado & $\begin{array}{l}\text { Mais de } 90 \% \text { das } \\
\text { doses nos } 4 \\
\text { primeiros meses } \\
\text { (saiu da pesquisa) }\end{array}$ & & \\
\hline $\begin{array}{l}\text { Joel } \\
30 \text { anos }\end{array}$ & 3 doses & $\begin{array}{l}\text { Nauseas } \\
\text { toleradas durante } \\
3 \text { meses }\end{array}$ & $\begin{array}{l}\text { Doses muito } \\
\text { irregulares durante } \\
6 \text { meses, em seguida } \\
5 \text { meses de interrupção }\end{array}$ & $\begin{array}{l}\text { Passou a } 2 \text { doses } \\
11 \text { meses depois } \\
\text { do início do } \\
\text { tratamento }\end{array}$ & $\begin{array}{l}\text { Mais de } 90 \% \text { das doses } \\
\text { nos últimos } 6 \text { meses } \\
\text { (17 meses após a } \\
\text { primeira prescrição) }\end{array}$ \\
\hline $\begin{array}{l}\text { Fabiana } \\
33 \text { anos }\end{array}$ & 2 doses & $\begin{array}{l}\text { Náuseas } \\
\text { pela manhã }\end{array}$ & $\begin{array}{l}\text { Mais de } 90 \% \text { das doses } \\
\text { nos } 4 \text { primeiros meses } \\
\text { (saiu da pesquisa) }\end{array}$ & & \\
\hline $\begin{array}{l}\text { Sofia } \\
34 \text { anos }\end{array}$ & 2 doses & $\begin{array}{l}\text { Fortes Náuseas } \\
\text { durante } 2 \text { meses }\end{array}$ & & & $\begin{array}{l}\text { Nenhuma dose perdida } \\
\text { em } 12 \text { meses }\end{array}$ \\
\hline $\begin{array}{l}\text { Cláudio } \\
34 \text { anos }\end{array}$ & 3 doses & Bem tolerado & $\begin{array}{l}\text { Mais de } 90 \% \text { das doses } \\
\text { nos } 4 \text { primeiros meses } \\
\text { (saiu da pesquisa) }\end{array}$ & $\begin{array}{l}\text { Passou a } 2 \text { doses } \\
22 \text { meses depois do } \\
\text { início do tratamento }\end{array}$ & $\begin{array}{l}\text { Mais de } 90 \% \text { das doses } \\
\text { nos últimos } 2 \text { meses } \\
\text { (24 meses após a } \\
\text { primeira prescrição) }\end{array}$ \\
\hline $\begin{array}{l}\text { Cirilo } \\
34 \text { anos }\end{array}$ & 2 doses & $\begin{array}{l}\text { Náuseas moderadas } \\
\text { erupção cutânea. } \\
\text { Neuropatia nos pés }\end{array}$ & $\begin{array}{l}\text { Mais de } 90 \% \text { das doses } \\
\text { nos } 4 \text { primeiros meses } \\
\text { (saiu da pesquisa) }\end{array}$ & & \\
\hline $\begin{array}{l}\text { Sebastião } \\
34 \text { anos }\end{array}$ & 2 doses & $\begin{array}{l}\text { Náuseas moderadas } \\
\text { pela manhã durante } \\
2 \text { meses }\end{array}$ & & & $\begin{array}{l}\text { Mais de } 90 \% \text { das doses } \\
\text { nos } 12 \text { primeiros meses }\end{array}$ \\
\hline $\begin{array}{l}\text { Edmundo } \\
36 \text { anos }\end{array}$ & 2 doses & $\begin{array}{l}\text { Neuropatia nos pés } \\
\text { (em regressão) }\end{array}$ & & & $\begin{array}{l}\text { Mais de } 90 \% \text { das doses } \\
\text { nos } 12 \text { primeiros meses }\end{array}$ \\
\hline $\begin{array}{l}\text { Leonardo } \\
39 \text { anos }\end{array}$ & 3 doses & $\begin{array}{l}\text { Náuseas pela manhã } \\
\text { durante } 2 \text { meses }\end{array}$ & $\begin{array}{l}\text { Mais de } 90 \% \text { das } \\
\text { doses }\end{array}$ & $\begin{array}{l}\text { Passou a } 2 \text { doses } \\
13 \text { meses depois do } \\
\text { início do tratamento }\end{array}$ & $\begin{array}{l}\text { Mais de } 90 \% \text { das doses } \\
\text { nos } 13 \text { primeiros meses }\end{array}$ \\
\hline $\begin{array}{l}\text { Elizabeth } \\
40 \text { anos }\end{array}$ & 2 doses & $\begin{array}{l}\text { Náuseas moderadas } \\
\text { durante } 2 \text { semanas }\end{array}$ & & & $\begin{array}{l}\text { Nenhuma dose perdida } \\
\text { em } 12 \text { meses }\end{array}$ \\
\hline $\begin{array}{l}\text { Camile } \\
46 \text { anos }\end{array}$ & 3 doses & $\begin{array}{l}\text { Náuseas dor de } \\
\text { cabeça, febre }\end{array}$ & $\begin{array}{l}\text { Mais de } 90 \% \text { das } \\
\text { doses }\end{array}$ & & $\begin{array}{l}\text { Mais de } 90 \% \text { das doses } \\
\text { nos } 15 \text { primeiros meses }\end{array}$ \\
\hline $\begin{array}{l}\text { Luis } \\
47 \text { anos }\end{array}$ & 3 doses & $\begin{array}{l}\text { Bem tolerado no } \\
\text { Início, Errupção } \\
\text { cutânea após } 8 \text { meses }\end{array}$ & $\begin{array}{l}\text { Perde mais de } 7 \\
\text { doses por semana }\end{array}$ & & $\begin{array}{l}\text { Menos de } 80 \% \text { das } \\
\text { doses nos } 15 \\
\text { primeiros meses }\end{array}$ \\
\hline $\begin{array}{l}\text { Paulo } \\
48 \text { anos }\end{array}$ & 3 doses & Bem tolerado & $\begin{array}{l}\text { Mais de } 90 \% \text { das } \\
\text { doses nos } 5 \\
\text { primeiros meses } \\
\text { (saiu da pesquisa) }\end{array}$ & & \\
\hline $\begin{array}{l}\text { Dominique } \\
51 \text { anos }\end{array}$ & 3 doses & Bem tolerado & $\begin{array}{l}\text { Perde cerca de } 5 \text { doses } \\
\text { por semana nos } 6 \\
\text { primeiros meses }-2 \\
\text { meses de interrupção }\end{array}$ & & $\begin{array}{l}\text { Menos de } 80 \% \text { das doses } \\
\text { nos } 10 \text { primeiros meses }\end{array}$ \\
\hline $\begin{array}{l}\text { Juarez } \\
56 \text { anos }\end{array}$ & 2 doses & Bem tolerado & & & $\begin{array}{l}\text { Mais de } 90 \% \text { das doses } \\
\text { nos } 12 \text { primeiros meses }\end{array}$ \\
\hline $\begin{array}{l}\text { Maurício } \\
57 \text { anos }\end{array}$ & 3 doses & $\begin{array}{l}\text { Bem tolerado } 3 \\
\text { meses, náuseas } \\
\text { incoercíveis em } \\
\text { seguida }\end{array}$ & $\begin{array}{l}\text { Mais de } 90 \% \text { das } \\
\text { doses nos } 3 \text { primeiros } \\
\text { meses }-5 \text { meses } \\
\text { de interrupção }\end{array}$ & $\begin{array}{l}\text { Passou a duas } \\
\text { doses } 8 \text { meses } \\
\text { depois do início do } \\
\text { tratamento }\end{array}$ & $\begin{array}{l}\text { Mais de } 90 \% \text { das doses } \\
\text { nos últimos } 6 \text { meses ( } 14 \\
\text { meses depois da } \\
\text { primeira prescrição) }\end{array}$ \\
\hline $\begin{array}{l}\text { Yvon } \\
68 \text { anos }\end{array}$ & 3 doses & Bem tolerado & $\begin{array}{l}\text { Perde cerca de } 3 \text { doses } \\
\text { por semana (saiu da } \\
\text { pesquisa) }\end{array}$ & & \\
\hline
\end{tabular}

